\title{
- FALSELY HIGH PRESSURE CURVE FROM THE RIGHT ATRIAL APPENDAGE
}

\author{
BY \\ B. W. JOHANSSON AND N.-M. OHLSSON \\ From the Cardiological Laboratory, Department of Medicine and the Radiological Department, \\ Allmänna Sjukhuset, Malmö, Sweden
}

Received August, 15, 1960

During cardiac catheterization it is usually not difficult to decide in which part of the heart the tip of the catheter lies. If the frontal view on the screen does not indicate this clearly, the patient can be rotated and the lateral view is often more helpful. Furthermore, the pressure curves in the right atrium, ventricle, and pulmonary trunk have very different characteristics. These characteristics are generally so pronounced that, even if deformed as a result of the underlying heart lesion, they usually provide a conclusive answer. There are, however, situations when the pressure curves are misleading.

During catheterization of a girl (Case 1) aged two and a half years, the tip of the catheter lay in the upper part of the right atrium, probably in the right atrial appendage (Fig. 1). The pressure

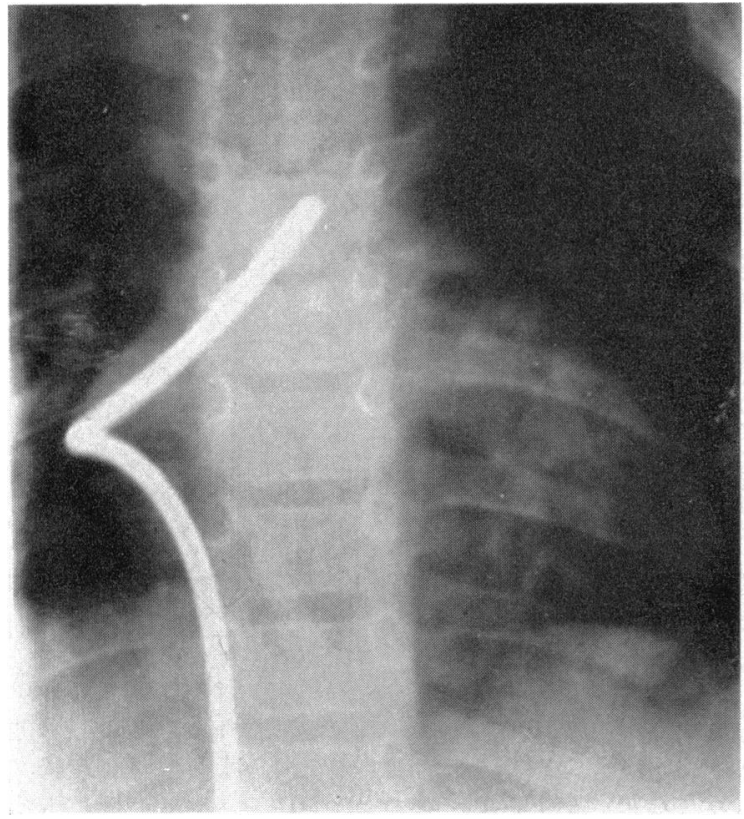

FIG. 1.-(A) Frontal view.

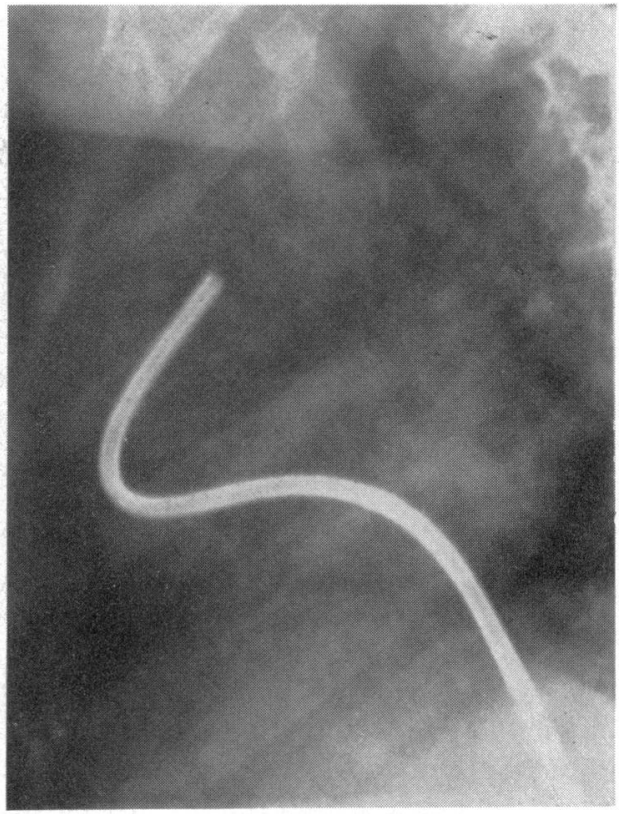

Fig. 1.-(B) Left oblique lateral view.

Catheter in position described in the text, i.e. with the tip in the right atrial appendage. The No. 8 Cournand catheter was introduced through the right saphenous vein, which is our routine in cases of this type. 
curve, however, showed a peak pressure, usually of about $25 \mathrm{~mm}$. and on one occasion of about 50 $\mathrm{mm}$. Hg. This pressure recording was obtained when the catheter was pressed more or less firmly against the wall. A withdrawal curve to the right atrium is depicted in Fig. 2, where it is seen that the upstroke begins earlier in relation to the QRS complex in the electrocardiogram than when the catheter tip was situated in the right ventricle (Fig. 3). When the catheter tip was still situated in

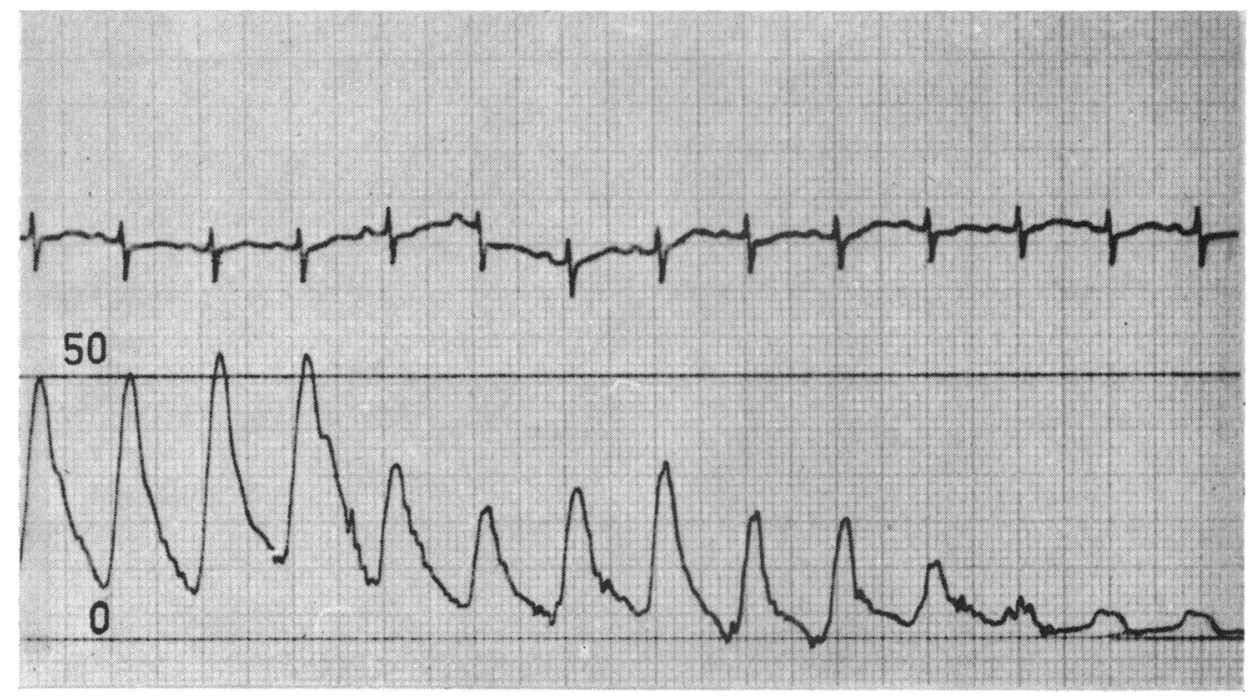

FIG. 2.-Case 1. Withdrawal curve from right atrial appendage to the right atrium in a $2 \frac{1}{2}$ year-old girl. The pressure curve was recorded with an Elema Mingograf no 42 through a Cournand catheter No. 8. The horizontal lines indicate 0 and $50 \mathrm{~mm}$. Hg respectively.

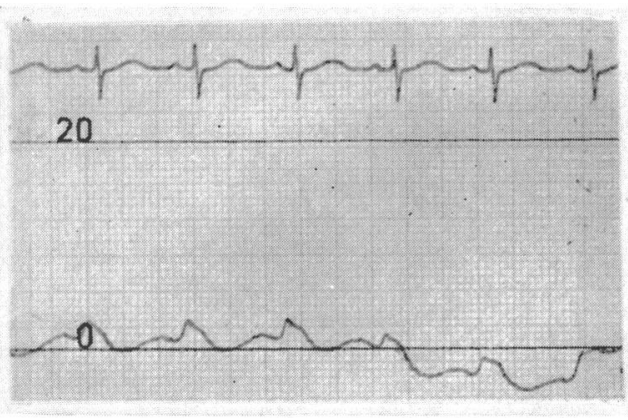

A

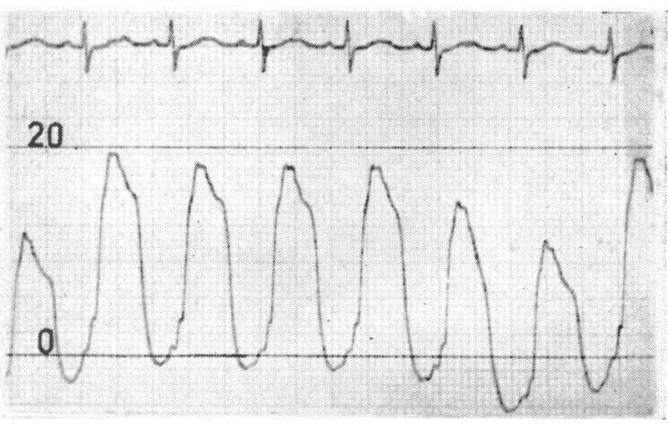

B

Fig. 3.-Pressure curve from the right atrium (A) and the right ventricle (B) of Case 1. The horizontal lines indicate 0 and $20 \mathrm{~mm}$. $\mathrm{Hg}$ respectively.

the position shown in Fig. 1, a small amount of contrast was injected. This revealed the contours of a small space, which in form and appearance was consistent with an atrial appendage. The findings on catheterization were normal except for this strange pressure curve. Selective angiocardiography was also normal. The patient had a grade 3 systolic murmur with maximal intensity in the fourth left intercostal space. The electrocardiogram showed a rsr's' complex in lead V1.

We suspected that the strange pressure curve, which without doubt was recorded with the tip of the catheter in the atrial appendage, was caused by the contraction of the wall when the 
catheter was pressed against it. Another possibility was propagation of contractions from the aorta or pulmonary artery to the appendage.

To test these two hypotheses we (1) tried to repeat these pressure curves at other catheterizations and (2) examined the pressure recordings from different parts of the atrial wall in a dog subjected to thoracotomy.

(1) At routine catheterization it is possible to get a pressure curve with higher peaks, when the catheter tip is pressed against the atrial appendage than when the catheter tip lies free in the middle of the atrium. Usually it is not possible to get values as high as in Case $1(25-50 \mathrm{~mm}$. $\mathrm{Hg})$ even if the catheter is firmly pressed against resistance; a value of $10-20 \mathrm{~mm}$. is more common. The pressure depends upon the force with which the catheter is pressed. In this connection it should be pointed out that this procedure is not entirely free of risk, especially in elderly persons, as perforation with hæmopericardium could result.

(2) In a dog subjected to thoracotomy a Cournand catheter was introduced into the right atrium via the saphenous vein. Fig. 4 shows the recordings obtained. It was obvious from this

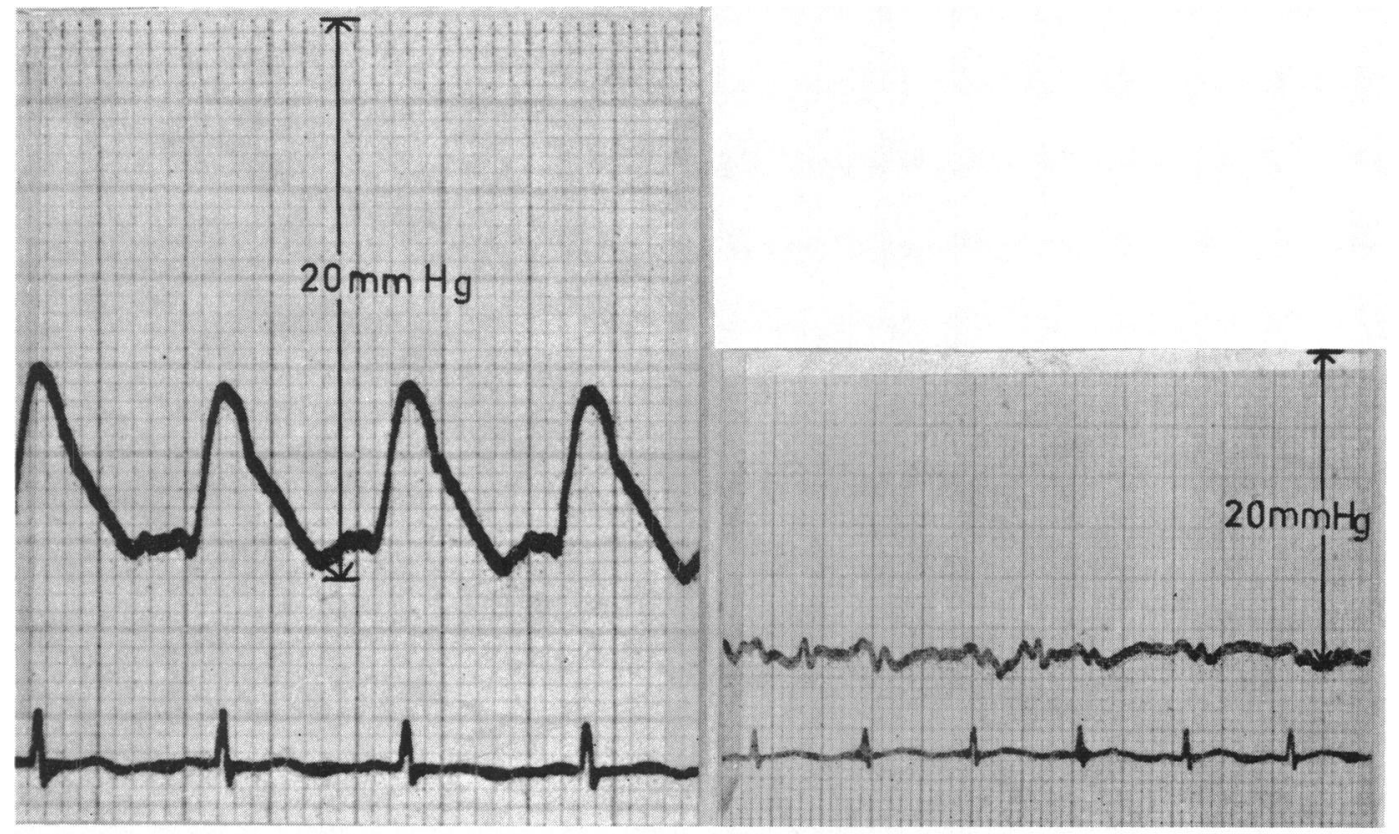

A

B

Fig. 4.-Pressure curves from the right atrial appendage of a dog. (A) Moderate pressure of the tip of the catheter against the wall. (B) Pressure curve obtained with the catheter tip free in the atrium.

experiment that the high pressures recorded were not caused by propagation of the pressure waves from the aorta, because similar recordings were obtained when the tip was removed from the atrial appendage and pressed instead against the lateral atrial wall. Furthermore the time relationships indicate that the peak comes too early to be of aortic origin.

Falsely high pressure peaks with a catheter situated in the right atrium have been reported by Fowler et al. (1957), who ascribe this finding to motions of the catheter tip. If this explanation is correct, it is probable that the motion presses the tip against the wall. In this way the high pressure peaks might have been produced by the contraction of the atrial musculature in our patient. It is probable that the high pressure obtained in the atrium, was produced by squeezing of the catheter tip between the muscle bundles described by Tandler (1926). Harris and Summerhayes 
(1955) reported pressures of $45-50 \mathrm{~mm}$. $\mathrm{Hg}$ obtained with the catheter far into the coronary sinus. These authors believe the explanation to be squeezing of blood from the capillaries and venules of the myocardium during contraction of the ventricles. In our cases it was never possible to get a blood sample, but it is obvious from Fig. 1 that the catheter tip was not in the coronary sinus.

\section{SUMMARY}

A pressure curve from the right atrium with peaks of about $25 \mathrm{~mm} . \mathrm{Hg}$ is described. The curve was obtained during catheterization of a girl, aged $2 \frac{1}{2}$ years.

Experience from other patients and an experiment on a dog indicate that these high peaks can be obtained both from the atrial appendage and the atrial wall and are produced by atrial contractions when the tip of the catheter is firmly pressed against the muscular wall.

The authors are greatly indebted to Drs. Arne Malm and Björn Sjöstrom at the Department of Thoracic Surgery, Malmö General Hospital, for surgical assistance.

\section{REFERENCES}

Fowler, N. O., Mannix, E. P., Jr., and Noble, W. (1957). Amer. Heart J., 53, 343.

Harris, P., and Summerhayes, J. L. V. (1955). Brit. Heart J., 17, 453.

Tandler, J. (1926). Lehrbuch der systematischen Anatomic. 3. Band. Das Gefäss-System. F. C. W. Vogel, Leipzig, p. 58. 